Stefan R. Ninkovic ${ }^{*}$

Univerzitet u Novom Sadu,

Filozofski fakultet doi: 10.19090/zop.2017.26.93-108

UDC: $005: 37.017$

005.96/96:371.1

Pregledni rad

\title{
KARAKTERISTIKE SAVREMENIH MODELA LIDERSTVA U OBRAZOVANJU**
}

\begin{abstract}
Apstrakt. Liderstvo je, posle kvaliteta poučavanja, najznačajniji faktor uspešnosti škole. U ovom radu analizirani su savremeni modeli liderstva u školi koji imaju podršku u rezultatima empirijskih radova. Predstavljeni su rezultati teorijskih razmatranja i empirijskih istraživanja o transformacionom, pedagoškom i distribuiranom liderstvu. Drugi deo rada posvećen je razmatranju osnovnih faktora koji posreduju u odnosu između školskog liderstva i uspešnosti školske organizacije. U tom smislu, govori se o ulozi profesionalnih zajednica nastavnika, profesionalnog razvoja nastavnika, školske klime i uključenosti roditelja u rad škole. Zaključuje se preporukama za školsku praksu i buduća istraživanja.
\end{abstract}

Ključne reči: škola, transformaciono liderstvo, pedagoško liderstvo.

\section{UVOD}

U poslednjih dvadeset godina polemiše se o strategijama sistemskih reformi obrazovanja (Fullan, 2009). Ističe se da se savremene škole sve više oslanjaju na timski rad, saradnju i demokratsko upravljanje. Stručnjaci naglašavaju da nove uloge direktora postaju presudne za unapređenje obrazovne efektivnosti odnosno postignuća učenika osnovnih i srednjih škola (Pont, Nushe, \& Moorman, 2008).

U naučnoj i stručnoj javnosti se više ne postavlja pitanje o važnosti liderstva u obrazovanju. Školski lideri unapređuju obrazovna postignuća

\footnotetext{
*Stefan Ninković, stefan.ninkovic@ff.uns.ac.rs

** Tekst je nastao tokom rada na projektu Značaj participacije u društvenim mrežama za prilagođavanje evrointegracijskim procesima (broj projekta 179037), finansiranom od strane Ministarstva prosvete, nauke i tehnološkog razvoja Republike Srbije.
} 
učenika kroz snažan uticaj na motivaciju nastavnika i radne uslove $\mathrm{u}$ njihovim školama (Leithwood, Harris, \& Hopkins, 2008; Robinson, Lloyd, \& Rowe, 2008). Iako je uočena potreba za kvalitetnim liderima u obrazovanju, još uvek su nedovoljno poznata liderska ponašanja koja rezultiraju željenim ishodima.

Osnovni cilj ovog rada jeste da se predstave karakteristike savremenih modela obrazovnog liderstva, prvenstveno onih koji postoje u školskoj praksi. Prvi deo rada odnosi se na pregled teorijskih razmatranja i rezultata empirijskih istraživanja pedagoškog, transformacionog i distribuiranog liderstva u školskom okruženju. Drugi deo rada posvećen je razmatranju osnovnih faktora posredstvom kojih lideri u obrazovanju ostvaruju svoje efekte na nastavu. U završnom delu rada izvode se preporuke za školsku praksu i buduća istraživanja.

\section{ZNAČAJ LIDERSTVA U OBRAZOVANJU}

Liderstvo se tipično definiše kao proces namernog uticanja koji rezultira postizanjem željenih ciljeva (Northouse, 2008; Yukl, 2008). Mnogi autori ukazuju na neophodnost razlikovanja liderstva i menadžmenta. Dok je menadžment usresređen na održanje funkcionalnosti i efikasnosti, liderstvo je zasnovano na viziji, promenama i vrednostima (Bush, 2008). S druge strane, reč je o dve međusobno povezane uloge koje je praktično teško razdvojiti.

Liderstvo je uočeno kao ključni korelat organizacione (Yukl, 2008), kao i školske uspešnosti (Hallinger, 2011; Lezotte \& Snyder, 2011). Leithwood i saradnici (2008) tvrde da je, posle kvalitetnog poučavanja, liderstvo najznačajniji prediktor učeničkih postignuća. Prethodna istraživanja su pokazala da liderstvo direktora škole utiče na različite elemente njenog funkcionisanja, uključujući stavove nastavnika i akademsko postignuće učenika (Shatzer, Caldarella, Hallam, \& Brown, 2014). Postoje dokazi da uspešni direktori utiču na povećanje vremena koje učenici provode u učenju, čak od dva do sedam meseci u toku školske godine (Branch, Hanushek, \& Rivkin, 2013). Liderstvo je značajan unutarškolski faktor koji utiče na socioemocionalne kompetencije učenika i nastavnika (Jennings \& Greenberg, 2009). 
Rezultati međunarodnih komparativnih studija učeničkih postignuća (PISA) pokazuju da su uspešnije one zemlje u kojima škole imaju veću autonomiju u donošenju odluka (Schleicher, 2012). Podizanje nivoa autonomije škola zahteva razvijanje odgovarajućih kompetencija lidera $u$ obrazovanju. Zato je u zemljama koje imaju kvalitetne školske sisteme usavršavanje direktora u obrazovanju uglavnom obavezno (Vican, Relja, \& Popović, 2016).

Prilagođavanje obrazovnog sistema potrebama savremenog društva dovodi do redefinisanja prioriteta obrazovnih politika. Može se očekivati da će u narednom periodu obrazovni sistem Srbije biti intenzivno usklađivan sa zahtevima Evropske unije. Strategija razvoja obrazovanja u Srbiji do 2020. godine (2012) predviđa otklanjanje slabosti prilikom izbora direktora, uvođenje sistema njihovog pripremanja i usavršavanja, kao i vrednovanje njihovog rada. U kontekstu povećanja autonomije škole na finansijskom, organizacionom i kurikularnom planu, kvalitet škole postaje u većoj meri uslovljen rukovođenjem, posebno direktorom i njegovim kompetencijama (Peko, Mlinarević, \& Gajger, 2009). Kao važne uloge lidera u obrazovanju, navode se upravljanje kurikulumom, praćenje i vrednovanje nastavnika, podržavanje profesionalnog razvoja nastavnika, kreiranje saradničke školske kulture i strateško upravljanje resursima (Pont, Nushe, \& Moorman, 2008).

$\mathrm{Na}$ osnovu postojeće literature, moguće je izdvojiti aktuelne modele školskog liderstva koji su predmet empirijskih istraživanja. Svaki model liderstva sastoji se iz specifičnih ponašanja i praksi koje bi direktor, stručni saradnici i nastavnici mogli da realizuju u svom radu. Rezultati istraživanja ovih modela školskog liderstva detaljnije su prikazani u narednom delu ovog rada.

\section{MODELI ŠKOLSKOG LIDERSTVA}

Pedagoško liderstvo

Dva najpoznatija modela liderstva u školi su pedagoško (instrukciono) i transformaciono (Hallinger, 2003). Koncept pedagoškog liderstva je nastao u okviru istraživanja korelata efektivnosti škola u SAD, kada je uočeno da su uspešnije one škole koje imaju direktore koji 
unapređuju nastavne procese. Takvi direktori su opisivani kao „lideri koji vrše akademski pritisak i postavljaju visoka očekivanja prema učenicima i nastavnicima" (Hallinger, 2005: 3).

Hallinger $(2003$; 2005) kao tri komponente pedagoškog liderstva navodi definisanje misije škole, rukovođenje nastavom i kreiranje pozitivne školske klime. Savremena shvatanja proširuju koncept pedagoškog liderstva i naglašavaju njegovu povezanost sa organizacionim menadžmentom. Uspešna instrukciona ponašanja direktora odnose se na selekciju nastavnika, pružanje mogućnosti za profesionalni razvoj, obezbeđivanje odgovarajućih resursa i zaštitu nastavnika od ometanja u poslu. U jednoj studiji je pronađena negativna povezanost između vremena koje direktor škole provede $u$ neformalnim posetama nastavnim časovima i postignuća učenika, posebno $u$ srednjim školama. S druge strane, vreme provedeno u usavršavanju nastavnika i razvoju školskih programa doprinosi boljim postignućima (Grissom, Loeb, \& Master, 2013).

U novije vreme shvaćen je značaj kompjuterske pismenosti pedagoških lidera s obzirom na ulogu tehnologije u obrazovanju. Digitalne kompetencije direktoru škole omogućavaju efikasnije realizovanje liderskih funkcija, poput analiziranja podataka o nastavi, saopštavanja povratne informacije ili prezentovanja sadržaja u okviru profesionalnog razvoja nastavnika (Gumus \& Akcaoglu, 2013). U tom smislu, od pedagoških lidera se očekuje da budu sposobni da koriste tehnologiju u cilju uspešnog realizovanja svakodnevnih zadataka.

\section{Transformaciono liderstvo}

Transformaciono liderstvo je usresređeno na razvoj ljudi i organizacije (Hallinger, 2003). Prema koncepciji koju je razvio Bernard Bass (Bass \& Riggio, 2006), osnovne dimenzije transformacionog liderstva su: a) idealizovani uticaj koji je u funkciji izazivanja snažnih emocija i potrebe da se podređeni identifikuju sa liderom, b) inspirativna motivacija predstavlja postavljanje visokih očekivanja, c) intelektualna stimulacija podrazumeva podsticanje inovativnosti podređenih i d) individualno uvažavanje potreba i 
sposobnosti. Teorija transformacionog liderstva obuhvata i dve dodatne kategorije ponašanja: transakciono liderstvo i neliderstvo.

Transformacioni lideri pozitivno utiču na motivaciju nastavnika kroz povezivanje misije i ciljeva škole sa ličnim prioritetima nastavnika. U slučaju transakcionog liderstva, motivacija nastavnika je zasnovana na nagradama zbog pridržavanja eksterno definisanih pravila, procedura i zadataka. S druge strane, transformaciono liderstvo povezuje rad sa ličnim vrednostima i preferencijama i dovodi do unutrašnje motivacije zaposlenih (Yukl, 2008). $\mathrm{Na}$ primer, dosadašnje studije pokazuju da je transformaciono liderstvo pozitivno povezano sa inovativnom klimom u školi (Moolenaar, Daly, \& Sleegers, 2010), posvećenošću nastavnika organizacionim vrednostima škole (Ross \& Gray, 2006), kao i akademskim postignućem učenika (Shatzer et al., 2014).

O značaju transformacionog školskog liderstva govore i rezultati emprijskih istraživanja koja su realizovana u Srbiji. U svojoj studiji JosanovVrgović i Pavlović (2014) došli su do podatka da je školsko vođenje orijentisano na ljude pozitivno povezano sa zadovoljstvom nastavnika $\mathrm{u}$ oblastima razvoja škole, odnosa sa kolegama i timskog rada. Takođe, u istom istraživanju je ustanovljeno da su nastavnici koji rade u osnovnim i srednjim školama najzadovoljniji sigurnošću sopstvenog posla. Terek i saradnici (2015) navode da transformaciono liderstvo u osnovnim školama u Srbiji unapređuje komunikaciju unutar škole i zadovoljstvo nastavnika kroz formiranje zajedničke vizije, intelektualnu stimulaciju i pravedno nagrađivanje zaposlenih. Ninković i Knežević Florić (2016) su ustanovili da individualno $\mathrm{i}$ grupno orijentisane dimenzije transformacionog liderstva značajno objašnjavaju kolektivnu efikasnost nastavnika koja predstavlja percepciju da kolektiv kojem nastavnici pripadaju može pozitivno da utiče na ishode učenika.

Osnovne razlike između transformacionog i pedagoškog liderstva tiču se nivoa promena u školi (Hallinger, 2003). Transformacioni lideri su orijentisani na građenje profesionalnih zajednica kroz isticanje potreba nastavnika i kroz povezivanje ciljeva škole sa ličnim ciljevima nastavnika (Urick \& Bowers, 2014). Takav stil liderstva povezuje rad sa željama i težnjama uključenih, čija osnovna motivacija postaje autonomna i intrinzična 
(Vican et al, 2014). U slučaju pedagoškog liderstva, pozitivna klima u školi rezultat je zajedničkog fokusa članova kolektiva na nastavu. Transformaciono liderstvo je preduslov distribuiranog liderstva (Harris, 2013) ili podeljene forme pedagoškog liderstva (Marks \& Printy, 2003).

Neki autori smatraju da su razlike između predstavljenih modela obrazovnog liderstva prenaglašene. Kao zajedničke karakteristike transformacionog i pedagoškog liderstva navode se (Leithwood \& Sun, 2012):

- proizvođenje osećaja zajedniče svrhe,

- razvoj klime visokih očekivanja i školske kulture usmerene na unapređenje poučavanja i učenja,

- ocenjivanje i nagrađivanje članova školskog kolektiva,

- intelektualna stimulacija i razvoj nastavnika,

- vidljivo modelovanje vrednosti u školi.

Rezultati prethodnih istraživanja dosledno pokazuju da pedagoško liderstvo ostvaruje veći doprinos akademskom postignuću učenika u odnosu na transformaciono liderstvo (Robinson et al., 2008). Kao posledica ovih saznanja, pojavile su se tvrdnje nekih istraživača da transformacionom liderstvu nedostaje fokus na nastavne procese. S druge strane, taj model obrazovnog liderstva neki su naučnici predložili kao odgovarajući u okolnostima dinamičnih reformi školskih sistema (Leithwood \& Jantzi, 2006). Važno je da novija saznanja (Printy, Marks, \& Bowers, 2009; Shatzer et al, 2014) ukazuju na potrebu integrisanja ova dva modela obrazovnog liderstva, prvenstveno zbog činjenice da određena transformaciona ponašanja takođe značajno utiču na postignuća učenika u školi.

U okviru obrazovne politike Srbije uočen je značaj liderske uloge direktora u obrazovanju. Na Univerzitetima u Kragujevcu i Novom Sadu akreditovan je master program Liderstvo u obrazovanju koji je usklađen sa ispitanim potrebama i najvažnijim preporukama koje su date u Pravilniku o standardima kompetencija direktora ustanova obrazovanja i vaspitanja (2013) i Strategiji razvoja obrazovanja u Srbiji do 2020. godine (2012). U narednom koraku ka profesionalizaciji pozicije direktora neophodno je uvođenje sistema licenciranja direktora predškolskih ustanova i škola. 


\section{Distribuirano liderstvo}

Najčešće kritike upućene praksi pedagoškog liderstva odnose se na pripisivanje uticaja, moći i autoriteta isključivo direktoru obrazovne institucije. Kao posledica toga, došlo je do zanemarivanja liderske uloge nastavnika i stručnih saradnika. Podeljeno pedagoško liderstvo, koje je nastalo na bazi kritika liderstva kao centriranog na direktora, akcenat stavlja na profesionalne zajednice i liderstvo nastavnika (Printy, Marks, \& Bowers, 2009). Sve je više rezultata empirijskih istraživanja koji pokazuju da kada liderstvo nije ograničeno na direktora, veće su šanse za organizaciono učenje i unapređenje rada škole (Harris, Leithwood, Day, Sammons, \& Hopkins, 2007).

U odnosu na hijerarhijske, horizontalne ili podeljene liderske strukture omogućavaju različitim pojedincima da imaju ulogu lidera, u zavisnosti od njihovih kompetencija. Pojačano interesovanje istraživača za fenomen deljenja liderskih funkcija posledica je razumevanja potrebe za uključivanjem nastavnika u donošenje odluka u školi. Podeljeno pedagoško liderstvo doprinosi da nastavnici preuzmu odgovornost za organizacione promene i rukovođenje.

Jedna od najvećih novina $u$ istraživanjima obrazovnog liderstva jeste uvođenje koncepta distribuiranog liderstva koji ima brojne sličnosti sa nastavničkim liderstvom (York-Barr \& Duke, 2004). Liderstvo nastavnika je važan činilac implementiranja školskih reformi i profesionalnog razvoja nastavnika. Putem nastavničkog liderstva škole postaju profesionalne zajednice učenja u kojima postoje preduslovi za unapređenje nastave i postignuća učenika (Vanblaere \& Devos, 2016). Liderstvo nastavnika je važna komponenta unapređenja rada škole i faktor koji doprinosi pozitivnim promenama u školi, te se u tom smislu može posmatrati kao novi pristup suočavanju sa izazovima obrazovnih reformi.

U Tabeli 1 uporedno su prikazani savremeni modeli školskog liderstva. Svaki od modela liderstva čine specifične prakse ili ponašanja koja imaju pozitivne efekte na ishode nastavnika i učenika. Može se reći da se predstavljeni modeli međusobno razlikuju na osnovu stavljanja naglaska na različite oblike ponašanja direktora škole. 
Tabela 1. Uporedni prikaz različitih modela školskog liderstva (prilagođeno iz: Urick \& Bowers, 2014)

\begin{tabular}{|c|c|c|c|}
\hline $\begin{array}{l}\text { Lidersko } \\
\text { ponašanje }\end{array}$ & $\begin{array}{l}\text { Transformaciono } \\
\text { liderstvo (Leithwood } \\
\quad \text { \& Sun, 2012) }\end{array}$ & $\begin{array}{c}\text { Pedagoško } \\
\text { liderstvo } \\
\text { (Hallinger, 2003) }\end{array}$ & $\begin{array}{c}\text { Distribuirano } \\
\text { liderstvo } \\
\text { (Printy et al., 2009) }\end{array}$ \\
\hline $\begin{array}{l}\text { Saopštavanje } \\
\text { misije }\end{array}$ & $\begin{array}{l}\text { Inspirativna } \\
\text { motivacija, } \\
\text { idealizovani uticaj, } \\
\text { kreiranje vizije, } \\
\text { visoka očekivanja }\end{array}$ & $\begin{array}{l}\text { Artikulisanje i } \\
\text { saopštavanje } \\
\text { ciljeva škole, } \\
\text { visoka očekivanja }\end{array}$ & $\begin{array}{l}\text { Snažno liderstvo } \\
\text { direktora }\end{array}$ \\
\hline $\begin{array}{l}\text { Podsticanje } \\
\text { profesionalnog } \\
\text { razvoja }\end{array}$ & $\begin{array}{l}\text { Individualno } \\
\text { uvažavanje, } \\
\text { intelektualna } \\
\text { stimulacija; } \\
\text { pružanje } \\
\text { individualizovane } \\
\text { podrške }\end{array}$ & $\begin{array}{l}\text { Podsticanje } \\
\text { profesionalnog } \\
\text { razvoja nastavnika }\end{array}$ & $\begin{array}{l}\text { Mogućnosti za } \\
\text { napredovanje } \\
\text { nastavnika u } \\
\text { autentičnom } \\
\text { kontekstu }\end{array}$ \\
\hline $\begin{array}{l}\text { Građenje osećaja } \\
\text { zajednice }\end{array}$ & $\begin{array}{l}\text { Idealizovani uticaj, } \\
\text { intelektualna } \\
\text { stimulacija, } \\
\text { podsticanje } \\
\text { uključenosti u } \\
\text { donošenje odluka }\end{array}$ & $\begin{array}{l}\text { Vidljivost } \\
\text { direktora, } \\
\text { podsticanje i } \\
\text { nagrađivanje } \\
\text { nastavnika }\end{array}$ & $\begin{array}{l}\text { Saradnja nastavnika } \\
\text { i direktora u cilju } \\
\text { analiziranja nastave }\end{array}$ \\
\hline $\begin{array}{l}\text { Koordinisanje } \\
\text { nastavnog } \\
\text { programa }\end{array}$ & $\begin{array}{l}\text { Instrukciona podrška, } \\
\text { zaštita nastavnika od } \\
\text { smetnji u radu }\end{array}$ & $\begin{array}{l}\text { Koordinisanje } \\
\text { kurikuluma, } \\
\text { evaluacija nastave, } \\
\text { praćenje } \\
\text { napredovanja } \\
\text { učenika }\end{array}$ & $\begin{array}{l}\text { Usklađivanje } \\
\text { aktivnosti u školi }\end{array}$ \\
\hline
\end{tabular}

Deljenje pedagoškog

Podsticanje

liderstva sa liderstva nastavnika nastavnicima

Uporedni prikaz pokazuje da između različitih modela liderstva postoji značajan stepen preklapanja i da lideri koji rade u školama mogu da kombinuju različite stilove vođenja. Studije realizovane u SAD (Urick \& Bowers, 2014) pokazuju da direktori škola obično ispoljavaju nekoliko 
stilova liderstva u obavljanju svoje uloge. Istraživači ukazuju na činjenicu da unapređenje nastavnih procesa pretpostavlja razvijanje ukupnog organizacionog kapaciteta škole. U tom smislu, govori se o potrebi da pedagoško liderstvo bude šire usmereno na organizacione uslove kao što su školska kultura i klima. S druge strane, savremena shvatanja transformacionog liderstva uključuju direktno unapređenje školskog kurikuluma i poučavanja. U poznatoj koncepciji transformacionog liderstva $\mathrm{u}$ školskom okruženju, koju je razvio Kenneth Leithwood (Leithwood \& Sun, 2012), jedna od važnih komponenti jeste unapređenje nastave.

\section{PROCESI UTICAJA LIDERSTVA U ŠKOLI}

Mnogi autori saglasni su da su efekti obrazovnog liderstva na nastavu posredovani različitim faktorima (Hallinger \& Heck, 2010; Leithwood et al, 2008). Generalno, istraživanja podržavaju zaključak da liderstvo doprinosi obrazovnim postignućima učenika kroz razvoj niza strukturalnih i organizacionih procesa koji definišu kapacitet škole za unapređenje nastave (Hallinger \& Heck, 2010). Ta saznanja podstakla su istraživače da se bave medijatorskim varijablama uticanja liderstva na postignuća učenika u školi (Leithwood, Patten, \& Jantzi, 2010). Razumevanje različitih načina na koje lideri u školi ostvaruju efekte na nastavu u fokusu je istraživača i praktičara, a posebno kreatora relevatnih programa obrazovanja lidera u obrazovanju (Rigby, 2014).

U skladu sa saznanjima da su efekti liderstva u školi uglavnom posredovani, odgovaranje na pitanje „kako” podrazumeva identifikovanje medijatora uticaja obrazovnog liderstva na ishode učenika. Sebastian i Allensworth (2012) su došli do saznanja da su osnovni medijatori uticaja transformacionog školskog liderstva na nastavu i učenje učenika: profesionalna zajednica učenja, kvalitet programa profesionalnog razvoja, školska klima i saradnja porodice i škole (Slika 1). 


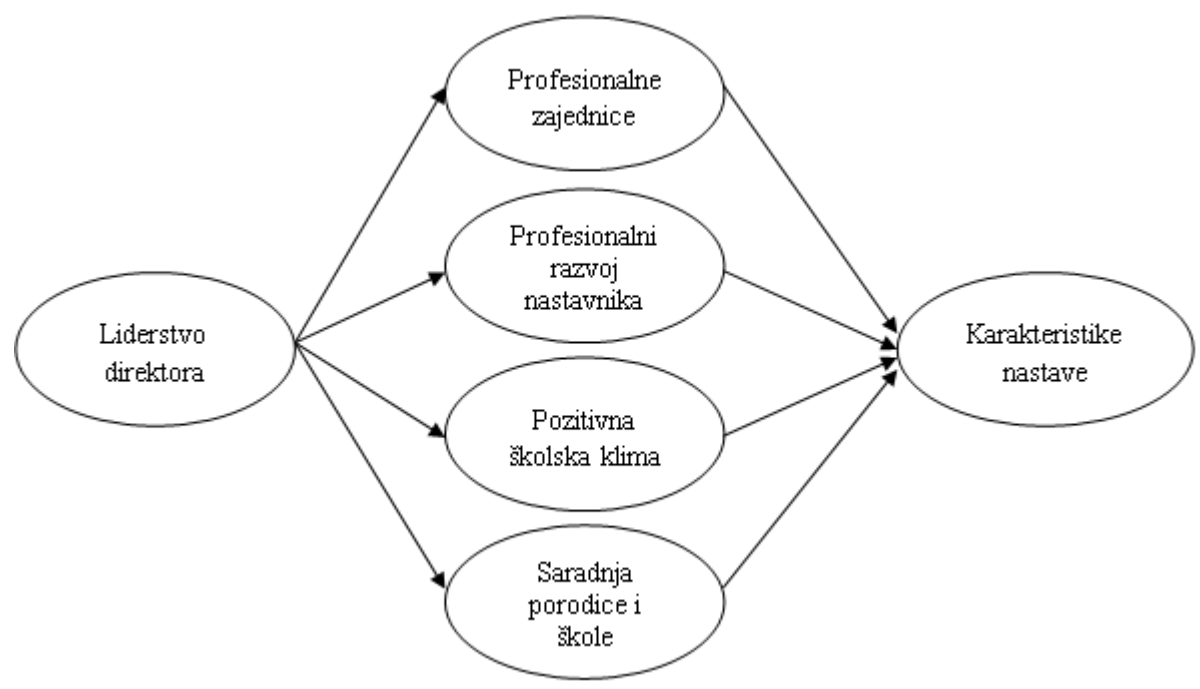

Slika 1. Relacije liderstva direktora, organizacionih faktora škole i karakteristika nastave (prilagođeno iz: Sebastian \& Allensworth, 2012)

Profesionalne zajednice učenja predstavljaju kolaborativno okruženje koje ima brojne pozitivne efekte na nastavnike i učenike. Drugim rečima, to su grupe nastavnika koji kritički preispituju sopstvenu praksu, na refleksivan, kolaborativan, inkluzivan i razvojni način (Stoll, Bolam, McMahon, Wallace, \& Thomas, 2006). Koncept profesionalnih zajednica zastupljen je u literaturi o profesionalnom učenju nastavnika jer deljenje znanja i praksi predstavlja značajan kontekst stručnog usavršavanja nastavnika i doprinosi kvalitetu poučavanja i učenja u školi. Kao osnovni aspekti profesionalnih zajednica nastavnika navode se podeljena odgovornost, refleksivni dijalog i deprivatizovana praksa (Vanblaere \& Devos, 2016).

Drugi značajan mehanizam putem kojeg direktor škole značajno utiče na nastavu jeste strukturisanje programa profesionalnog razvoja nastavnika. Prethodne studije pokazuju da je uspešan profesionalni razvoj nastavnika usresređen na nastavne ishode, promovisanje saradnje nastavnika, pružanje mogućnosti za refleksiju i kritičko mišljenje (Little, 2003). Direktor škole trebalo bi da ima ključnu ulogu u razvijanju i održavanju efektivnog profesionalnog učenja nastavnika.

Važan faktor akademskog i socijalnog razvoja učenika jeste uključivanje roditelja u rad škole. Roditeljska uključenost je značajan resurs 
za brojne inicijative unapređenja škole, od poboljšanja bezbednosti u školi, do sprečavanja problema učeničkog absentizma i podsticanja akademske socijalizacije kod kuće. Partnerski odnos između porodice i škole treba da se ispolji kroz povećano uključivanje roditelja u aktivnosti škole. Od direktora škole se očekuje da ima vodeću ulogu u građenju klime poverenja i saradnje između škole i roditelja (Polovina, 2008).

Školska klima je determinanta pozitivnog razvoja, prevencije rizika i postignuća dece i mladih (Thapa, Cohen, Guffey, \& Higgins-D’Alessandro, 2013). Rezultati istraživanja (Sebastian \& Allensworth, 2012) ukazuju da direktor škole najveći uticaj na nastavu ima upravo kroz kreiranje pozitivne školske klime. Ono što treba istaći jeste da promene školskog etosa podrazumevaju socijalne kompetencije direktora. Takođe, rad u pozitivnom okruženju doprinosi instrinzičnoj motivaciji nastavnika, kao i zadovoljstvu poslom te smanjuje tendenciju napuštanja profesije (Thapa et al, 2013).

Važan aspekt školske klime, koja je pozitivno povezana sa obrazovnim postignućima učenika, jeste akademski pritisak (Hallinger, 2005). Percepcija akademskog pritiska dovodi do toga da nastavnici u svom radu imaju visoke standarde, veruju u sposobnosti učenika, a postignuće se prepoznaje i ceni. Akademski pritisak školski lideri mogu da razvijaju kroz postavljanje visokih očekivanja, razjašnjavanje ciljeva škole i praćenje napredovanja učenika.

U ovom radu predstavljeni su neki od faktora za koje postoje empirijski dokazi da posreduju u odnosu između obrazovnog liderstva i školskih postignuća učenika. Istraživanja mehanizama uticaja školskog liderstva na nastavne ishode pružaju važne preporuke za vaspitno-obrazovnu praksu. To je posebno važno imajući u vidu preopterećenost direktora administrativnim obavezama (Vican et al, 2016). Školski lideri u svom radu treba da se rukovode saznanjima o organizacionim, nastavnim i porodičnim varijablama koje snažno utiču na ishode školskog obrazovanja.

\section{ZAKLJUČAK}

U ovom radu predstavljeni su rezultati izabranih studija o savremenim modelima školskog liderstva. Analizirane su koncepcije transformacionog, 
pedagoškog i distribuiranog liderstva koje imaju značajnu podršku u empirijskim istraživanjima koja su realizovana prevashodno u Zapadnoj Evropi i SAD. U skladu sa razmatranim teorijskim raspravama i empirijskim saznanjima, može se zaključiti da škole mogu imati brojne koristi od liderskih ponašanja i praksi koje su obuhvaćene savremenim modelima obrazovnog liderstva.

U budućim istraživanjima bilo bi korisno empirijski ispitati u kojoj meri su pomenuti modeli zastupljeni u obrazovnim institucijama u Srbiji, kao što je to već urađeno u drugim zemljama (Urick \& Bowers, 2014). Na taj bi se način, na primer, došlo do uvida da li uspešni direktori škola u Srbiji paralelno ispoljavaju visok nivo transformacionog i pedagoškog liderstva. To je posebno značajno imajući u vidu saznanja da prisustvo i efekti stilova vođenja zavise od nacionalne kulture (Jogulu, 2010). U tom smislu, važna istraživačka tema jeste zavisnost modela obrazovnog liderstva od socijalnokulturnog konteksta.

\title{
CHARACTERISTICS OF CONTEMPORARY MODELS OF LEADERSHIP IN EDUCATION
}

\begin{abstract}
Following the quality of classroom instruction, leadership is the most important factor affecting the school performance. The paper analyzes the contemporary models of school leadership, which are supported by the results of empirical studies. The paper presents the results of theoretical considerations and empirical research on transformational, pedagogical and distributed leadership. The second part of the paper discusses the main factors mediating the relationship between school leadership and the performance of the school organization. In that sense, the author discusses the role of teacher professional communities, teacher professional development, the school climate, and the involvement of parents in the school activities. The paper concludes with recommendations for the school practicum and future research.
\end{abstract}

KEY WORDS: school, transformational leadership, pedagogical leadership. 


\section{REFERENCE}

Bass, B. M., \& Riggio, R. E. (2006). Transformational leadership. New Jersey: Lawrence Erlbaum Associates.

Branch, G. F., Hanushek, E. A., \& Rivkin, S. G. (2013). School leaders matter. Education Next, 13(1), 1-8.

Bush, T. (2008). From management to leadership: semantic or meaningful change? Educational Management Administration \& Leadership, 36(2), 271-288.

Fullan, M. (2009). Large-scale reform comes of age. Journal of Educational Change, 10(2-3), 101-113.

Grissom, J. A., Loeb, S., \& Master, B. (2013). Effective instructional time use for school leaders longitudinal evidence from observations of principals. Educational Researcher, 42, 433-444.

Gumus, S., \& Akcaoglu, M. (2013). Instructional leadership in Turkish primary schools: An analysis of teachers' perceptions and current policy. Educational Management Administration \& Leadership, 41(3), 289-302.

Hallinger, P. (2003). Leading educational change: Reflections on the practice of instructional and transformational leadership. Cambridge Journal of Education, 33(3), 329-352.

Hallinger, P. (2005). Instructional leadership and the school principal: A passing fancy that refuses to fade away. Leadership and Policy in Schools, 4(3), 221-239.

Hallinger, P. (2011). Leadership for learning: lessons from 40 years of empirical research. Journal of Educational Administration, 49(1), 3145.

Hallinger, P., \& Heck, R. H. (2010). Collaborative leadership and school improvement: Understanding the impact on school capacity and student learning. School Leadership and Management, 30(2), 95-110.

Harris, A. (2013). Distributed Leadership Friend or Foe? Educational Management Administration \& Leadership, 41(5), 545-554.

Harris, A., Leithwood, K., Day, C., Sammons, P., \& Hopkins, D. (2007). Distributed leadership and organizational change: Reviewing the evidence. Journal of Educational Change, 8(4), 337-347. 
Jennings, P. A., \& Greenberg, M. T. (2009). The prosocial classroom: Teacher social and emotional competence in relation to student and classroom outcomes. Review of Educational Research, 79(1), 491525 .

Jogulu, U. D. (2010). Culturally-linked leadership styles. Leadership \& Organization Development Journal, 31(8), 705-719.

Josanov-Vrgovic, I., \& Pavlovic, N. (2014). Relationship between the school principal leadership style and teacher's job satisfaction in Serbia. Montenegrin Journal of Economics, 10(1), 43-57.

Leithwood, K., Harris, A., \& Hopkins, D. (2008). Seven strong claims about successful school leadership. School Leadership and Management, 28(1), 27-42.

Leithwood, K., \& Jantzi, D. (2006). Transformational school leadership for large-scale reform: Effects on students, teachers, and their classroom practices. School effectiveness and School Improvement, 17(2), 201227.

Leithwood, K., Patten, S., \& Jantzi, D. (2010). Testing a conception of how school leadership influences student learning. Educational Administration Quarterly, 46(5), 671-706.

Leithwood, K., \& Sun, J. (2012). The nature and effects of transformational school leadership a meta-analytic review of unpublished research. Educational Administration Quarterly, 48(3), 387-423.

Lezotte, L. W., \& Snyder, K. M. (2011). What effective schools do: Reenvisioning the correlates. Bloomington, IN: Solution Tree Press.

Little, J. W. (2003). Inside teacher community: Representations of classroom practice. Teachers College Record, 105(6), 913-945.

Marks, H. M., \& Printy, S. M. (2003). Principal leadership and school performance: An integration of transformational and instructional leadership. Educational Administration Quarterly, 39(3), 370-397.

Moolenaar, N. M., Daly, A. J., \& Sleegers, P. J. (2010). Occupying the principal position: Examining relationships between transformational leadership, social network position, and schools' innovative climate. Educational Administration Quarterly, 46(5), 623-670. 
Ninković, S. R., \& Knežević Florić, O. Č. (2016). Transformational school leadership and teacher self-efficacy as predictors of perceived collective teacher efficacy. Educational Management Administration \& Leadership, 1-16. doi:1741143216665842

Northouse, P. (2008). Liderstvo: teorija i praksa. Beograd: DATA STATUS.

Peko, A., Mlinarević, V., \& Gajger, V. (2009). Učinkovitost vođenja u osnovnim školama. Odgojne znanosti, 11(2), 67-84.

Polovina, N. (2008). Doprinos škole građenju partnerstva sa roditeljima. Zbornik Instituta za pedagoška istraživanja, 39(2), 347-366.

Pont, B., Nushe, D., \& Moorman, H. (2008). Improving School Leadership: policy and practice. Paris: OECD .

Pravilnik o standardima kompetencija direktora ustanova obrazovanja $i$ vaspitanja. (2013). „Službeni glasnik Republike Srbije”, br. 38/2013.

Printy, S., Marks, H., \& Bowers, A. (2009). Integrated leadership: How principals and teachers share transformational and instructional influences. Journal of School Leadership, 19, 504-532.

Rigby, J. G. (2014). Three logics of instructional leadership. Educational Administration Quarterly, 50(4), 610-644.

Robinson, V. M., Lloyd, C. A., \& Rowe, K. J. (2008). The impact of leadership on student outcomes: An analysis of the differential effects of leadership types. Educational Administration Quarterly, 44(5), 635-674.

Ross, J. A., \& Gray, P. (2006). Transformational leadership and teacher commitment to organizational values: The mediating effects of collective teacher efficacy. School Effectiveness and School Improvement, 17(2), 179-199.

Schleicher, A. (2012). Preparing teachers and developing school leaders for the 21st century: Lessons from around the world. Paris: OECD Publishing.

Sebastian, J., \& Allensworth, E. (2012). The influence of principal leadership on classroom instruction and student learning: A study of mediated pathways to learning. Educational Administration Quarterly, 48(4), 626-663. 
Shatzer, R. H., Caldarella, P., Hallam, P. R., \& Brown, B. L. (2014). Comparing the effects of instructional and transformational leadership on student achievement: Implications for practice. Educational Management Administration \& Leadership, 42(4), 445-459.

Stoll, L., Bolam, R., McMahon, A., Wallace, M., \& Thomas, S. (2006). Professional learning communities: A review of the literature. Journal of Educational Change, 7(4), 221-258.

Strategija razvoja obrazovanja u Srbiji do 2020. godine, „Službeni glasnik Republike Srbije" br. 107/2012.

Thapa, A., Cohen, J., Guffey, S., \& Higgins-D’Alessandro, A. (2013). A review of school climate research. Review of Educational Research, 83(3), 357-385.

Terek, E., Glušac, D., Nikolic, M., Tasic, I., \& Gligorovic, B. (2015). The Impact of Leadership on the Communication Satisfaction of Primary School Teachers in Serbia. Educational Sciences: Theory and Practice, 15(1), 73-84.

Urick, A., \& Bowers, A. J. (2014). What are the different types of principals across the United States? A latent class analysis of principal perception of leadership. Educational Administration Quarterly, 50(1), 96-134.

Vanblaere, B., \& Devos, G. (2016). Relating school leadership to perceived professional learning community characteristics: A multilevel analysis. Teaching and Teacher Education, 57, 26-38.

Vican, D., Relja, R., \& Popović, T. (2016). Liderska uloga ravnatelja u obrazovanju. U N. Alfirević, J. Barušić, J. Pavičić, \& R. Relja, Školska učinkovitost i obrazovni menadžment: ususret smernicama istraživanja i javne politike u jugoističnoj Evropi (pp. 89-108). Zagreb: Denona.

York-Barr, J., \& Duke, K. (2004). What do we know about teacher leadership? Findings from two decades of scholarship. Review of Educational Research, 74(3), 255-316.

Yukl, G. (2008). Rukovođenje u organizacijama. Jastrebarsko: Naklada Slap. 